\title{
О.Л. Туровський
}

Державний університет телекомунікацій, Київ

\section{АНАЛІЗ ЕФЕКТИВНОСТІ ЗАСТОСУВАННЯ ДВОХЕТАПНОГО АЛГОРИТМУ ОЦІНКИ НЕСУЧОЇ ЧАСТОТИ ФАЗОМОДУЛЬОВАНОГО СИГНАЛУ СУПУТНИКОВОЇ СИСТЕМИ ЗВ'ЯЗКУ ПРИ ПЕРЕДАЧІ ДАНИХ В БЕЗПЕРЕРВНОМУ РЕЖИМІ}

В роботі узагальнено прочедуру та сформовано двохетапний алгоритм оцінки несучої частоти фазомодульованого сигналу супутникової системи зв'язку при передачі даних в безперервному режимі з врахуванням умови невизначеності всіх параметрів сигналу. Досягнення мінімального інтервалу спостереження в поданому алгоритмі оцінки несучої частоти забезпечується використанням функиії швидкого перетворення Фур'є. 3 метою аналізу ефективності вказаного алгоритму проведено моделювання процесу оцінки несучої частоти фазомодульованого сигналу супутникової системи зв'язку при передачі даних в безперервному режимі та отримані функиіональні залежності максимуму частоти в спектрі сигналу та мінімальна дисперсія оцінки несучої частоти. Аналіз оцінки проведено на основі порівняння співвідношення отриманої мінімальної дисперсії оцінки несучої частоти і теоретично можливого кордону мінімальної дисперсії.

Ключові слова: очінка несучої частоти, мінімально гранична дисперсія оцінки, очінка максимуму частоти, функиія швидкого перетворення Фур'є, алгоритм оцінки частоти сигналу.

\section{Вступ}

Використання в супутникових системах зв'язку фазової модуляції сигналу, що призначений для передачі корисної інформації в безперервному режимі, породжує проблему частотної невизначеності сигналу, що приймається, по частоті.

Для демодуляторів супутникових модемів, що працюють з безперервним вхідним сигналом, при роботі в умовах частотної невизначеності сигналу найбільш значущою $є$ проблема синхронізації по частоті несучого коливання. Вказане завдання синхронізації фактично зводиться до оцінки істинних параметрів сигналу, що приймається [1].

Найкращі результати може дати сумісна оцінка невідомих параметрів сигналу. Однак на практиці реалізувати таку оцінку в каналі з низькою енергетикою і з великою частотною невизначеністю сигналу, що приймається, в безперервному режимі не представляється можливим. Тому оцінка зміщення несучої частоти сигналу, що приймається, відносно номінального значення проводить до того, як включаються інші процедури синхронізації, а саме: синхронізація по фазі і синхронізація по тактовій частоті [1-2].

Постановка задачі. Для вирішення завдання оцінки несучої частоти ФМ сигналу в умовах невизначеності інформації про початкову фазу сигналу $(\varphi)$, про величину його затримки $(\tau)$ і про передану інформаційну послідовність $(d)$ в ряді робіт обгрунтовується доцільність застосування правила максимальної правдоподібності. Відомо, що використання правила максимальної правдоподібності для оцінки несучої частоти (МП-оцінка) забезпечує аси- мптотично ефективні і асимптотично незміщені іiі оцінки [3; 5].

При наявності інформації про параметри $\{d$, $\varphi, \tau\}$ МП-оцінка несучої частоти $v$ може забезпечити мінімальну граничну дисперсію, яка буде визначатися нижнім кордоном Крамера-Рао [2-3].

Сам процес оцінки несучої частоти повинен забезпечити оцінку максимуму частоти в спектрі сигналу при мінімальній дисперсії оцінки несучої частоти за максимально короткий інтервал оцінки [3-4].

В свою чергу, розробка нових та удосконалення існуючих алгоритмів оцінки, що базуються на вище описаному процесі, вимагає аналізу ефективності їх застосування. Такий аналіз необхідно проводити відносно умов, факторів та параметрів, які визначають особливість передачі та прийому фазомодульованого сигналу фазокогерентними системами супутникового зв'язку в безперервному режимі.

Аналіз останніх досліджень і публікацій. Питанню оцінки несучої частоти сигналу, що приймається системою зв'язку в безперервному режимі, розробки порядку проведення вказаної оцінки, та оцінки їі ефективності присвячено ряд робіт.

Викладений в роботі [5] алгоритм оцінки несучої частоти фазомодульованого сигналу, що передається в безперервному режимі, заснований на МПоцінці, дозволяє здійснити оцінку максимуму частоти в спектрі сигналу при мінімальній дисперсії оцінки за мінімально короткий інтервал.

Але представлений алгоритм потребує аналізу його ефективності, результати якого в вказаній роботі розкриті та представлені не повністю. 
Автори роботи [6] запропонували алгоритм сумісної оцінки несучої частоти, іiі синхронізації та визначення зсуву несучої частоти в каналах 3 аддитивним білим гаусівським шумом. Запропонований алгоритм використовує фільтр частот 3 наступною вибіркою вхідних імпульсів по важливості, враховує попередній розподіл параметрів оцінки та включає рекомендації по повторній вибірці для вирішення проблеми виродження і точної настройки оціночних значень частоти вхідного сигналу. Вказаний алгоритм не передбачає визначення мінімальної дисперсії оцінки, а в роботі відсутній матеріал щодо оцінки його ефективності при застосуванні за призначенням.

У статті [7] розглядається запропонований авторами метод здійснення синхронізації послідовності, що розширюється в умовах значного перевищення рівня шуму над рівнем інформаційного сигналу. Для синхронізації використовується службовий канал, який працює на одній частоті з інформаційним. В запропонованому авторами алгоритмі синхронізації відсутні данні та процедури обрахування, що враховують інтервал оцінки та мінімальну дисперсію оцінки. Подані в роботі результати оцінки ефективності запропонованого алгоритму не в повній мірі розкривають його можливість щодо оцінки фазомодульованого сигналу супутникової системи зв'язку.

В роботі [8] запропонований варіант технічної реалізації швидкодіючого алгоритму відновлення несучої частоти методом безпосередньої підстройки фази опорного генератора з одночасним усуненням неоднозначності фази і виділення кадрової синхронізації при використанні узгоджених фільтрів з послідовностями Баркера. Використання вказаного алгоритму передбачає попередню оцінку несучої частоти вхідного сигналу, але без визначення та врахування інтервалу оцінки та дисперсії оцінки.

Автор роботи [9] пропонує підхід до зменшення похибки оцінювання несучої і символьної частоти сигналів 3 цифровою модуляцією методами, що базуються на аналізі частотних характеристик сигналу. В основу підходу покладено розрахунок першої похідної функції спектральної щільності та пошук нуля ітераційним методом хибного положення. Подані в роботі результати оцінки запропонованого підходу не в повній мірі розкривають його можливості щодо застосування в супутникових системах зв'язку.

В роботі [10] на основі відносних кореляційних характеристик псевдошумової послідовності розроблений алгоритм оцінки несучої частоти, що використовує преамбулу з вказаною послідовністю. Результати оцінки вказаного алгоритму, що подані в роботі, показали його відносну ефективність щодо точності оцінки, економії щодо ресурсів системи і стійкість при нестійкому стані каналу зв'язку. Пи- тання зменшення інтервалу оцінки несучої та оцінка ефективність роботи системи при оцінці частоти в роботі не розглядалися.

В роботах [11-12] розглядаються питання підвищення точності оцінки несучої частоти сигналу, що приймається, збільшення швидкодії системи оцінки несучої частоти, ресурсозберігання системи прийому сигналу в умовах нестійкого стану каналу прийому вхідного сигналу та низького співвідношення сигнал/шум. Подані в роботі алгоритми не передбачають визначення мінімальної дисперсії оцінки, а в роботах відсутній матеріал щодо повної оцінки його ефективності при застосуванні в системах супутникового зв'язку.

Таким чином, аналіз ефективності алгоритму оцінки несучої частоти фазомодульованого сигналу фазокогерентних систем супутникового зв'язку, що передають сигнал в безперервному режимі, що може забезпечити оцінку максимуму частоти в спектрі сигналу при мінімальній дисперсії оцінки несучої частоти за максимально короткий інтервал оцінки є актуальною науковою задачею.

В якості критерію, по якому можна провести вищезазначений аналіз, оберемо співвідношення дисперсії оцінок, що отримані в результаті використання запропонованого алгоритму двохетапної процедури оцінки в відповідності з теоретичними кордонами таких дисперсій.

Мета роботи: розробка та аналіз ефективності застосування двохетапного алгоритму оцінки несучої частоти фазомодульованого сигналу супутникової системи зв'язку при передачі даних в безперервному режимі $з$ врахуванням умови невизначеності всіх параметрів сигналу.

\section{Виклад основного матеріалу}

\section{1. Формалізація постановки задачі на розробку алгоритму оцінки}

Основне завдання аналізу ефективності алгоритму оцінки несучої частоти полягає в тому, щоб методами математичного моделювання визначити, як співвідносяться дисперсії оцінок, що отримані в результаті використання запропонованої в роботі [5] двохетапної процедури оцінки в відповідності з теоретичними кордонами.

В ході моделювання будемо генерувати підрахунки комплексної огибаючої сигналу, що приймається [5; 13]:

$$
Z_{n}=e^{j\left(2 \pi \nu \frac{n}{F_{d}}\right)} \sum_{k} d_{k} h\left(\frac{n}{F_{d}}-k T-\tau\right)+\omega_{n},
$$

де $F_{d}$ - частота дискретизації сигналу;

$\omega_{n}$ - відрахунок аддативного гаусівського шуму.

Приймалось, що величина $v$ характеризується 
рівномірним розподілом в діапазоні $\left[-v_{\max }, v_{\max }\right]$, де $v_{\max }=\frac{1}{T}$. Сигнал генерується з випадковою начальною фазою $\varphi$, рівномірно розподіленою в діапазоні $[-\pi, \pi]$. Величина $\tau$ генерується від датчика випадкових чисел з рівномірним розподілом і міняється в діапазоні $[0, T]$.

Коефіцієнт округлення фільтра Найквіста $a=0.4$. Моделювання проводимо для трьох випадків модуляції, а саме ФМ-2, ФМ-4 і ФМ-8. Частота дискретизації в ході моделювання вибиралась таким чином, щоб виконувалась умова співвідношення $F d T=8$. Вибір такого співвідношення частоти дискретизації і тактової частоти сигналу що поймається пояснимо наступним.

При помножені фази для ФМ-8 здійснюється 8ми кратне розширення спектру. Для припинення ефекту накладення спектрів частота дискретизації комплексної огибаючої сигналу, що приймається повинна бути не меншою, чим в 8 раз більш тактової частот цього сигналу.

Розглянемо двохетапну процедуру оцінки несучої частоти ФМ сигналу [5; 13-16].

\section{2. Перший етап оцінки}

На першому етапі проводиться МП-оцінка несучої частоти сигналу, що приймається на основі (2).

Обчислювальна процедура першого етапу полягає в наступному:

1. Обраховувались $N_{f}$ елементів $Z_{k}$ комплексного перетворення Фур'є сигналу, що приймається в відповідності до стандартів алгоритму ШПФ:

$$
Z_{k}=\frac{1}{N_{f}} \sum_{n=0}^{N_{f}^{-1}} Z_{n} \exp \left(-\frac{j 2 \pi n k}{N_{f}}\right),
$$

де $Z_{n}$ - відрахунок комплексної огибаючої сигналу, що приймається;

$$
k=0,1, \ldots, N_{f}-1
$$

2. Обраховувались відліки амплітудного спектру приймаємого сигналу

$$
G_{k}=\left|Z_{k}\right| \text {. }
$$

3. Здійснювалось перетворення отриманого амплітудного спектру до виду спектру смугового сигналу

$$
S R_{k}=\left\{\frac{G_{k}+\frac{N_{f}}{2}, k=0,1, \ldots, \frac{N_{f}}{2}-1}{G_{k}+\frac{N_{f}}{2}, k=\frac{N_{f}}{2}, \frac{N_{f}}{2}+1, \ldots, \frac{N_{f}}{2}-1}\right\} .
$$

4. Обраховувались відліки згортки амплітудного спектру з АЧХ узгодженого фільтру (УФ):

$$
\begin{gathered}
S W_{m}=S R_{m+\frac{N_{f}}{2}}+ \\
+\sum_{k=1}^{M_{1}-1} H_{k}\left[S R_{m+\frac{N_{f}}{2}+k}+S R_{m+\frac{N_{f}}{2}-k}\right],
\end{gathered}
$$

де $m=-N_{\max }, \ldots, N_{\max }$,

$$
N_{\max }=\left[\frac{V_{\max }}{F_{d}} N_{f}\right],
$$

$N_{k}$ - відлік АЧХ УФ.

Для $N_{\max }$ можна записати

$$
N_{\max }=\left\{\cos \left[\frac{\pi}{4 a}\left|\frac{2 k}{K}\right|-1+a\right]\right\} .
$$

При умовах $\frac{|k| \leq M_{0}}{\frac{M_{0} \leq|k| \leq M_{1}}{|k| \geq M_{1}}}$

де $m_{d}=F_{d} T$;

$$
\begin{aligned}
& M_{0}=\left[\frac{1-a}{2 m_{d}} N_{f}\right] ; \\
& M_{1}=\left[\frac{1+a}{2 m_{d}} N_{f}\right] .
\end{aligned}
$$

5. Обраховувались величини зміщення несучої частоти сигналу, що приймається, відносно номінального значення:

$$
\bar{v}_{0}=\arg \left\{\underset{-N_{\max } \leq m \leq N_{\max }}{\operatorname{Max}}\left\{S W_{m}\right\}\right\} * \frac{F_{d}}{N_{f}} .
$$

В процесі моделювання процедури першого етапу були вибрані наступні параметри: довжина інтервалу спостереження склала $K=256$ і 512 інформаційних символів.

Довжина швидкого перетворення Фур'є (ШПФ) $N_{f}$ безсумнівно пов'язана 3 довжиною інтервалу спостереження $N_{f}=m_{d} K$.

В нашому випадку $m_{d}=8$. Тому для $K=256$ $N_{f}=2048$ а $K=512$ відповідає $N_{f}=4096$.

Тут і в подальшому при реалізації обчислювальних процедур в безперервному режимі вибір значень $K$ по ступеню двійки обумовлений відносною простотою реалізації алгоритмів ШПФ довжини $2^{n}$, де $n$ - позитивне ціле число.

В процесі моделювання відношення $E_{b} / N_{0}$ мінялось в розглянутому діапазоні з шагом 0.25 дБ. При кожному оцінюванні $E_{b} / N_{0}$ алгоритм оцінювання реалізовувався $N_{s}=1000$ разів.

Нормована дисперсія обраховувалась наступним чином:

$$
\overline{\sigma_{v}^{2}} T^{2}=\frac{1}{N S} \sum_{i=1}^{N_{S}}\left[\left(v_{i}-v_{0} \overline{(}(i)\right)\right]^{2}
$$


де $v_{i}$ - зміщення несучої частоти сигналу, що приймається? при $i$-й реалізації алгоритму оцінювання;

$\bar{v}_{0}(i)$ - величина оцінки даного зміщення при $i$-й реалізації алгоритму оцінювання;

$N_{s}$ - число експериментів.

Залежність нормування дисперсії оцінки несучої частоти від відношення $E_{b} / N_{0}$, отримане по результатам моделювання для $K=256$ і 512, подані на рис. 1.

На рис. 1. суцільними лініями зображені відповідні заданим умовам нормовані кордони $\sigma_{v}^{2 *} T^{2}$.

Необхідно відмітити, що дисперсія оцінки частоти несучого коливання ФМ-сигналу, отриманого при реалізації процедури оцінки першого етапу, практично співпадає з відповідною граничною дисперсією.

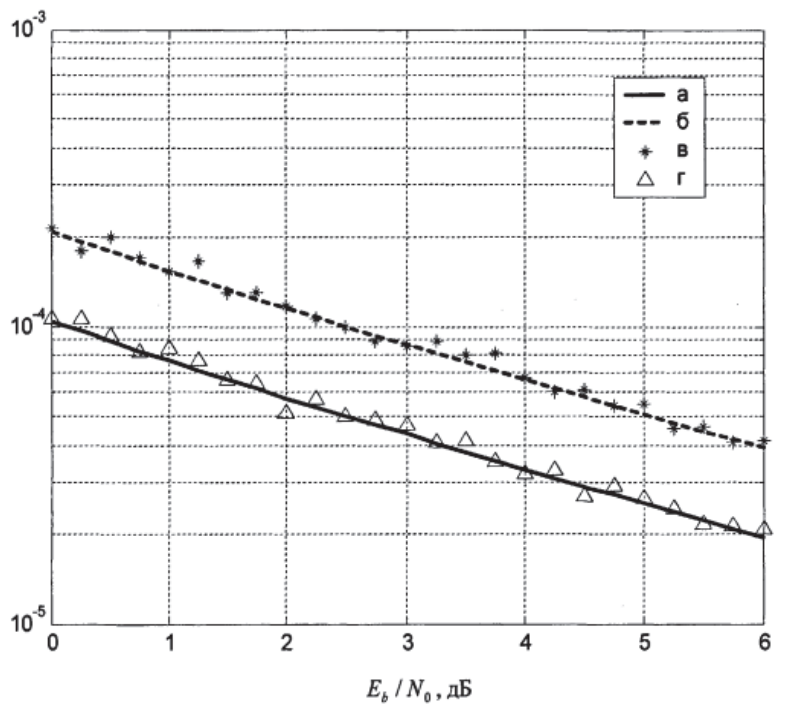

Рис. 1. Вид модуляції-ФМ-4:

Нормування МГД оцінок несучої частоти $\left(\sigma_{v}^{2 *} T^{2}\right)$, $\mathrm{a}-\mathrm{K}=512 ; \mathrm{b}-\mathrm{K}=256$.

Нормування дисперсії оцінок несучої частоти

$\left(\sigma_{v}^{2 *} T^{2}\right)$, в $-\mathrm{K}=256, \Gamma-\mathrm{K}=256$

Джерело: розроблено автором.

\section{3. Другий етап оцінки}

На другому етапі проводиться зняття модуляції і оцінка частоти максимуму в спектрі сигналу $y_{n}$.

Для оцінки частоти розглянутого максимуму проводились наступні операції.

1. Обраховувались $N_{f}$ елементів $Y_{k}$ комплексного перетворення Фур'є сигналу $y_{n}$ в відповідності з стандартним алгоритмом ШПФ.

$$
y_{k}=\frac{1}{N_{f}} \sum_{n=1}^{N_{f}-1} y_{n}{ }^{*} \exp \left(-\frac{j 2 \pi n k}{N_{f}}\right),
$$

де $k=0,1, \ldots, N_{f}-1$.

2. Обчислювався відлік амплітуди спектру

$$
y_{k}=\frac{1}{N_{f}} \sum_{n=1}^{N_{f}-1} y_{n} * \exp \left(-\frac{j 2 \pi n k}{N_{f}}\right) .
$$

3. Обчислювався відлік $W_{k}$ шляхом перетворення амплітудного спектру $G_{k}$ до виду спектру смугового сигналу з використанням перетворення (1).

4. Визначався номер спектрального підрахунку $M_{p}$, такий що

$$
M_{p}=\arg \left\{\frac{\max }{-N_{i}+\frac{N_{f}}{2} \leq k \leq N_{i}+\frac{N_{f}}{2}}\left\{W_{k}\right\}\right\},
$$

де $N_{i}$ - деяка фіксована величина.

4. Для більш точної оцінки частоти максимуму спектра сигналу $y_{n}$ застосовується процедура дихтомічного пошуку, що застосовується для оцінки несучої частоти ФМ сигналу в пакетному режимі.

Про спектр сигналу на виході схеми множення фази можна зробити висновок по спектрам сигналів, що подані на рис. 2 і рис. 3. На рисунках подані нормовані спектри сигналів, отримані в ході моделювання при реалізації процедури множення фази для сигналів ФМ-2 і ФМ-4.

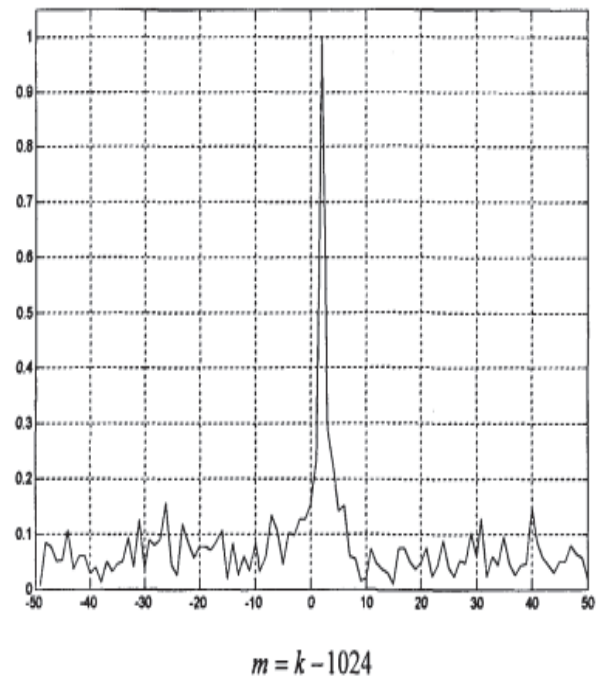

Рис. 2. Нормовані амплітудні спектри сигналу на виході схеми множення фази.

Вид модуляції - ФМ-2, $E_{b} / N_{0}=3$ дБ, v =0 Джерело: розроблено автором.

Спектри отримані довкола точки $M_{p}$ для $N_{f}=4096$ і к $=-50, \ldots, 50$.

На графіках мають місце виразні спектральні максимуми, шляхом оцінки яких обраховується оцінка другого етапу.

Таким чином, після завершення процедури другого етапу, прикінцева оцінка частоти несучого 
коливання ФМ сигналу обраховується наступним чином:

$$
\bar{v}=\bar{v}_{0}+\frac{1}{M_{\varphi}} f_{M_{i}},
$$

де $f_{M_{i}}$ - оцінка, отримана при реалізації вищеподаної ітеративної процедури;

$M_{i}$ - число ітерацій процедури дихтомічного пошуку;

$M_{\varphi}-$ обсяг алфавіту сигналу.

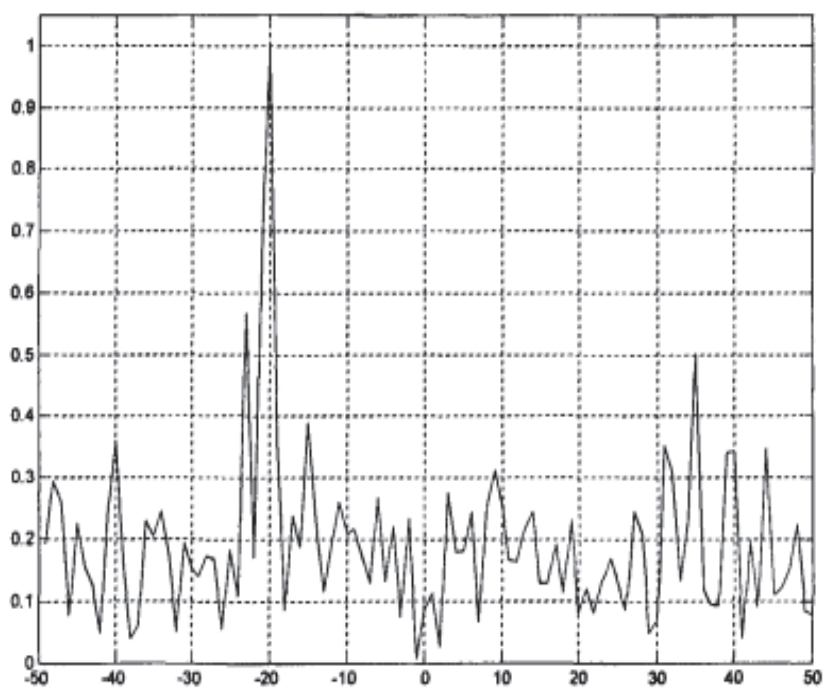

$$
m=k-1024
$$

Рис. 3. Нормований амплітудний спектр сигналу на виході схеми множення фази. Вид модуляції-ФМ-4, $E_{b} / N_{0}=3$ дБ, $v=0$ Джерело: розроблено автором.

\section{Висновки}

В роботі узагальнено процедуру оцінки та сформовано на іiі основі двохетапний алгоритм оцінки несучої частоти фазомодульованого сигналу супутникової системи зв'язку при передачі даних в безперервному режимі з врахуванням умови невизначеності всіх параметрів сигналу.

Вказаний алгоритм дає змогу здійснити двохетапну оцінку несучої частоти по правилу максимальної правдоподібності з врахуванням умови невизначеності всіх параметрів сигналу, що приймається супутниковою системою зв'язку в безперервному режимі при мінімальному інтервалі спостереження.

Досягнення мінімального інтервалу спостереження в поданому алгоритмі оцінки несучої частоти забезпечується використання функції швидкого перетворення Фур'є та двома етапами оцінки:

- етапу визначення мінімальної дисперсії оцінки несучої частоти;

- етапу оцінки максимуму частоти в спектрі сигналу.

Аналіз ефективності оцінки вказаного алгоритму проводився на основі порівняння співвідношення отриманих мінімальної дисперсії оцінки несучої частоти та теоретично можливого кордону мінімальної дисперсії.

Подані в роботі результати моделювання по запропонованому алгоритму та їх аналіз показав практичну реалізуємість поданих функціональних залежностей та актуальність застосування запропонованого алгоритму для оцінки несучої частоти сигналу, що приймається супутниковою системою зв'язку в безперервному режимі.

\section{Список літератури}

1. Горбатий І.В. Системи дистанційного зондування Землі з космосу: монографія / І.В. Горбатий. - Львів: СПОЛОМ, 2011. - 612 с.

2. Левин Б.Р. Теоретические основы статистической радиотехники / Б.Р. Левин. -М.: Радио и связь, 1989. -656 с.

3. Шестаков А.Л. Оценка несущей частоты случайной последовательности импульсов методом Прони / А.Л. Шестаков, А.С. Семенов, О.Л. Ибряева // Вестник ЮУрГУ. - 2009. - № 37(170). - С. 106-115.

4. Tong Zhao. Cramer-Rao Lower Bounds for the Joint Delay-Doppler Estimation of an Extended Target / Tong Zhao, Tianyao Huang // IEEE Global Conference on Signal and Information Processing (GlobalSIP), 14-16 Dec. 2015. Orlando, FL, USA. - Orlando. - 2015. - P. 17-24.

5. Туровський О.Л. Алгоритм оцінки несучої частоти фазомодульованого сигналу супутникової системи зв'язку при передачі даних в безперервному режимі з використанням функції швидкого перетворення Фур'є / О.Л. Туровський // Звя'зок. - 2020. - № 2(142). - С. 55-61.

6. Nasir A.A. Particle filters for joint timing and carrier estimation: Improved resampling guidelines and weighted bayesian cramer-rao bounds / A.A. Nasir, S Durrani, R.A. Kennedy // IEEE Trans. Commun. - 2012. - № 60(5). - P. 1407-1419.

7. Тихомиров А.В. Синхронизация в системах с прямым расширением спектра / А.В.Тихомиров, Е.В. Омельянчук, А.Ю. Семенова // Инженерный вестник Дона. - 2019. - № 9(60). - С. 69-70.

8. Быстродействующий алгоритм восстановления несущей частоты и фазовой синхронизации в модемах с QPSK модуляцией / А.В. Садченко, О.А. Кушниренко, Е.К. Кошелев, В.И. Бондар // Технология и конструирование в электронной аппаратуре. - 2018. - № 1. - С. 28-36.

9. Нагорнюк О.А. Покращення точності оцінювання несучої та символьної частоти сигналів з цифровою модуляцією / О.А. Нагорнюк // Проблеми створення, випробування, застосування та експлуатації складних інформаційних систем: Зб. наук. праць ЖВІ НАУ. -2013. - Вип. 8. - С. 62-70.

10. Исследование алгоритма оценки смещения несущей частоты, использующего преамбулу с псевдошумовой последовательностью / Куигфенг Джинг, Уейжи Жонг, Юпинг Лу, Ксиаоджу Ян // Известия высших учебных заведений. Радиоэлектроника. - 2013. - Т. 56, № 1. - С. 34-42.

11. Juan A.M. Block synchronization algorithms for UWB-OFDM systems / A.M. Juan, G.G. Cecilia // Digit. Signal Process. - 2011. - Vol. 21(2). - P. 187-295. 
12. Weizhi Zhongю Research on carrier frequency offset estimation algorithm based on PN sequence preamble in OFDM system / Weizhi Zhong, Yuping Lu, Xiaoju Yan // Radioelectronics and Communications Systems. - 2013. - Vol. 56. - P. 29-35.

13. Lyons R.G. Understanding Digital Signal Processing / R.G. Lyons. - Boston: Prentice Hall, 2010. - 992 p.

14. D'Amico A. Cramer-Rao Bound for Clock Drift in UWB Ranging Systems / A. D'Amico, U. Mengali, L. Taponecco // IEEE Wireless Communication Letters. - 2013. - № 2(6). - P. 591-594.

15. Фомин А.И. Синхронизация цифровых радиосистем передачи информации / А.И. Фомин. - Москва: СайнсПресс, 2008. - 280 с.

16. Залманзон Л.А. Преобразования Фурье, Уолша, Хаара и их применение в управлении, связи и других областях / Л.А. Залманзон. - Москва: Наука, 1989. - 496 с.

Відомості про автора:

Туровський Олександр Леонідович кандидат технічних наук доцент професор кафедри

Державного університету телекомунікацій, Київ, Україна

https://orcid.org/0000-0002-4961-0876

\section{Information about the author:}

\section{Olexandr Turovsky}

Candidate of Technical Sciences Associate Professor

Professor of Department

of State University of Telecommunications,

Kyiv, Ukraine

https://orcid.org/0000-0002-4961-0876

\title{
АНАЛИЗ ЭФФЕКТИВНОСТИ ПРИМЕНЕНИЯ ДВУХЭТАПНОГО АЛГОРИТМА ОЦЕНКИ НЕСУЩЕЙ ЧАСТОТЫ ФАЗОМОДУЛИРОВАНОГО СИГНАЛА СПУТНИКОВОЙ СИСТЕМЫ СВЯЗИ ПРИ ПЕРЕДАЧЕ ДАННЫХ В НЕПРЕРЫВНОМ РЕЖИМЕ
}

\section{А.Л. Туровский}

В данной работе обобщена процедура и сформирован двухэтапный алгоритм оченки несущей частоты фазомодулированного сигнала спутниковой системы связи при передаче данных в непрерывном режиме с учетом условий неопределенности всех параметров сигнала. Достижение минимального интервала наблюдения в представленном алгоритме оиенки несущей частоты обеспечивается использованием функиии быстрого преобразования Фурье. С иелью анализа эффективности указанного алгоритма проведено моделирование процесса оиенки несущей частоты фазомодулированного сигнала спутниковой системы связи при передаче данных в непрерывном режиме и полученные функциональные зависимости максимума частоты в спектре сигнала и минимальная дисперсия оценки несущей частоть. Анализ оценки проводился на основе сравнения соотношения полученной минимальной дисперсии оценки несущей частоты и теоретически возможного гранищы минимальной дисперсии.

Ключевые слова: оценка несущей частоты сигнала, минимально предельная дисперсия оценки несущей частоты, оиенка максимума частоты в спектре сигнала, функиия быстрого преобразования Фурье, алгоритм оценки частоты сигнала.

\section{ANALYSIS OF THE EFFICIENCY OF APPLICATION OF THE TWO-STAGE ALGORITHM OF THE CARRIER MODULATION OF THE PHASOMODULATED SIGNAL OF THE SATELLITE COMMUNICATION SYSTEMS}

\author{
O. Turovsky
}

The use in satellite communication systems of phase modulation of a signal designed to transmit useful information in a continuous mode creates the problem of frequency uncertainty of the signal. For demodulators of satellite modems operating with a continuous input signal, the most significant problem is the synchronization of the carrier frequency. This synchronization task is actually reduced to estimating the true parameters of the signal, namely the estimation of the carrier frequency. In turn, the estimation process itself should provide an estimate of the maximum frequency in the spectrum of the input signal at a set minimum variance of the estimate for the minimum observation interval. This paper summarizes the estimation procedure and forms on its basis a two-stage algorithm for estimating the carrier frequency of the phase-modulated signal of the satellite communication system in data transmission in continuous mode, taking into account the uncertainty of all signal parameters. Achieving the minimum observation interval in the given carrier frequency estimation algorithm is ensured by using the fast Fourier transform function. In order to evaluate the efficiency of this algorithm, the process of estimating the carrier frequency of the phase-modulated signal of the satellite communication system during continuous data transmission is modeled and the functional dependences of the maximum frequency in the signal spectrum and the minimum variance of carrier frequency estimation are obtained. The analysis of the evaluation efficiency was performed on the basis of comparing the ratio of the obtained minimum variance of the carrier frequency estimation and the theoretically possible limit of the minimum variance. The results of modeling according to the proposed algorithm presented in the work showed the practical feasibility of the presented functional dependencies and the relevance of the proposed algorithm for estimating the carrier frequency of the signal received by the satellite communication system in continuous mode.

Keywords: signal carrier frequency estimation, minimum limiting variance of carrier frequency estimation, estimation of maximum frequency in the signal spectrum, fast Fourier transform function, signal frequency estimation algorithm. 